Chronic Obstructive Pulmonary Diseases: Journal of the COPD Foundation

\title{
Review
}

\section{Prevention of Exacerbations in Chronic Obstructive Pulmonary Disease: Knowns and Unknowns}

\author{
Alvar Agustí, MD, PhD, FRCP, FERS, ${ }^{1}$ Peter M. Calverley, DSc, FMedSci, ${ }^{2}$ Marc Decramer, MD, PhD, ${ }^{3}$ Robert A. \\ Stockley, MD, DSc, FRCP, FERS, ${ }^{4}$ Jadwiga A.Wedzicha, MD $^{5}$
}

\section{Abstract}

The 2011 recommendations of the Global initiative for chronic Obstructive Lung Disease (GOLD) constituted a major paradigm shift in COPD management since they set 2 major goals for the assessment and management of patients: (1) the reduction of their current level of symptoms (i.e., treat the patient today); and (2) the reduction of their risk of exacerbations (i.e., prevent them tomorrow). Exacerbations are not only an important clinical endpoint in patients with COPD, but they are also a risk factor themselves for additional adverse outcomes since they have been shown to increase the risk for mortality, to accelerate the decline in pulmonary function, and to decrease health status and quality of life. Despite their importance, many unanswered questions related to exacerbations remain. The purpose of this review is to discuss: (1) knowns and unknowns in our current understanding of exacerbations, (2) what known factors increase their risk, and (3) how to best prevent them.

Abbreviations: computed tomography, CT; Evaluation of COPD Longitudinally to Identify Predictive Surrogate Endpoints, ECLIPSE; Body mass index-airway Obstruction-Dyspnea-Exercise capacity index, BODE; COPD Assessment Test, CAT; the EXAcerbation of Chronic Pulmonary Disease Tool, EXACT; hazard ratio, HR; confidence interval, CI; long-acting muscarinic antagonist, LAMA; long-acting $\beta$ 2agonist, LABA; inhaled corticosteroids, ICS; TOwards a Revolution in COPD Health, TORCH; Prevention Of Exacerbations with Tiotropium in COPD, POET-COPD; obstructive sleep apnea, OSA; forced expiratory flow between $25 \%$ and $75 \%$ of forced vital capacity, $\mathbf{F E F} \mathbf{2 5 - 7 5}$ forced expiratory volume in 1 second, FEV $_{\mathbf{1}}$; interleukin, IL; St. George's Respiratory Questionnaire, SGRQ; tumor necrosis factor, TNF; white blood cell, WBC;

Funding Support: Not Applicable

Date of Acceptance: July 24, 2014

Citation: Agustí A, Calverley PM, Decramer M, Stockley RA, Wedzicha JA. Prevention of exacerbations in chronic obstructive pulmonary disease: knowns and unknowns. J COPD F. 2014;1(2):166-184. doi: http://dx.doi.org/10.15326/jcopdf.1.2.2014.0134

1 Institut del Tòrax, Hospital Clínic, Barcelona, Spain

2 Clinical Sciences Center, University Hospital Aintree, Liverpool, United Kingdom

3 Respiratory Division, University Hospitals, Leuven, Belgium

4 Lung Investigation Unit, University Hospitals of Birmingham, Edgbaston, Birmingham, United Kingdom

5 Airways Disease Section, National Heart and Lung Institute, Imperial College London, United Kingdom

\section{Address correspondence to:}

Alvar Agustí, MD, PhD, FRCP, FERS

Director, Institut del Tòrax, Hospital Clínic

Villarroel 170, Escala 3

Planta 5, 08036

Barcelona, Spain

Tel: +34932271701

Fax: +34932279868

e-mail: alvar.agusti@clinic.ub.es

\section{Keywords:}

COPD; exacerbations; chronic bronchitis; emphysema;smoking; inflammation; therapy 


\section{Introduction}

The 2011 recommendations of the Global initiative for chronic Obstructive Lung Disease (GOLD) propose that the assessment and treatment of COPD patients should be structured around 2 major goals: the reduction of the current level of symptoms (i.e., treat the patient today); and, the reduction of the risk of future exacerbations of the disease (COPD exacerbations) (i.e., prevent them tomorrow). ${ }^{1}$ The latter is a major step forward for COPD, in many ways similar to that achieved by cardiologists decades ago when they realized that they should treat not only symptoms (dyspnea) or acute events (angina), but also to reduce the risk of future events by decreasing arterial blood pressure and/or cholesterol levels. Further, COPD exacerbations are not only important clinical endpoints in themselves, ${ }^{2-5}$ but also increase the risk for mortality ${ }^{6,7}$ accelerate the decline in pulmonary function, ${ }^{8-11}$ worsen cardiovascular comorbidities, ${ }^{12,13}$ decrease health status, ${ }^{14,15}$ and impair activities of daily living. ${ }^{16-18}$

Despite their importance, many questions related to COPD exacerbations remain unanswered. The purpose of this paper is to review the current state of the art with respect to prevention of COPD exacerbations. Specifically, it discusses: (1)knowns and unknowns in our current understanding of COPD exacerbations, (2) factors that increase their risk, and (3)how to prevent them. It does not discuss the adequacy of the treatment of these episodes ${ }^{1,19}$ which has been the subject of recent research. ${ }^{20,21}$ It is important to note, however, that this is not a systematic review of the literature and basically reflects the opinions of the authors.

\section{COPD Exacerbations: Knowns and Unknowns}

According to GOLD "an exacerbation of COPD is an acute event characterized by a worsening of the patient's respiratory symptoms that is beyond normal day-today variations and leads to a change in medication." This definition is straightforward, yet it has several caveats that deserve discussion. First, it is entirely based on the perception by the patient of an increase in symptoms, which is known to vary significantly among individuals. It is entirely possible, therefore, that different patients may have different perception thresholds. This has been well established in patients with asthma, ${ }^{22,23}$ but has been much less investigated in COPD. In support of this possibility is the fact that the use of diary cards to monitor COPD patients at home has shown that they may experience increases in symptoms that are indistinguishable from those occurring during exacerbations that receive treatment but are not reported/treated; so-called unreported exacerbations. ${ }^{14,24}$ Alternatively, poor family and social support may result in some patients reporting more episodes of symptom deterioration than they would have otherwise. These 2 examples illustrate the poor specificity and the unknown reproducibility of the currently accepted definition of an exacerbation of COPD. Given that this definition is used in many clinical trials, it is likely that exacerbation rates in trials are generally under-reported. It is fair to acknowledge that our current understanding of this topic is limited and that identification and proper validation of a diagnostic biomarker(s) for exacerbation is urgently needed. Using again the cardiology analogy, this would be equivalent to diagnosing or missing an acute myocardial infarction based on symptoms alone (without the aid of electrocardiography and biochemical changes). We used to do this once upon a time, but fortunately for patients with acute coronary artery disease, things have changed.

Second, some, but not all, patients appear to be particularly prone to suffer repeated exacerbations, the so-called frequent exacerbators. ${ }^{8,14}$ Whether this represents true recurrence of exacerbations or, at least in some cases, treatment failure is difficult to dissect (Figure 1$)^{25}$ since exacerbations cluster and frequent exacerbators are more likely to have recurrent exacerbations. $^{26}$ Likewise, how much time must elapse between events to consider them as independent episodes is still debated ${ }^{25,26}$ since it is necessary to know when the event starts and stops before a new event can be identified. It is plausible that different individual thresholds and/or degrees of social support (as discussed above) confound the rate of exacerbations reported by any single patient. Similarly, adherence to therapy is also likely to influence the frequency or persistence of exacerbations in COPD patients.

Third, exacerbations are heterogeneous. Traditionally, they have been related to viral and/or bacterial respiratory infection. ${ }^{27,28}$ In support of this possibility, Papi et al showed that bacteria and/or viruses could be detected in $78 \%$ of 64 patients hospitalized for exacerbations. $^{29}$ To explore the role of infection in the pathobiology of exacerbations further, Mallia et al ${ }^{30}$ 


\section{Figure 1.}
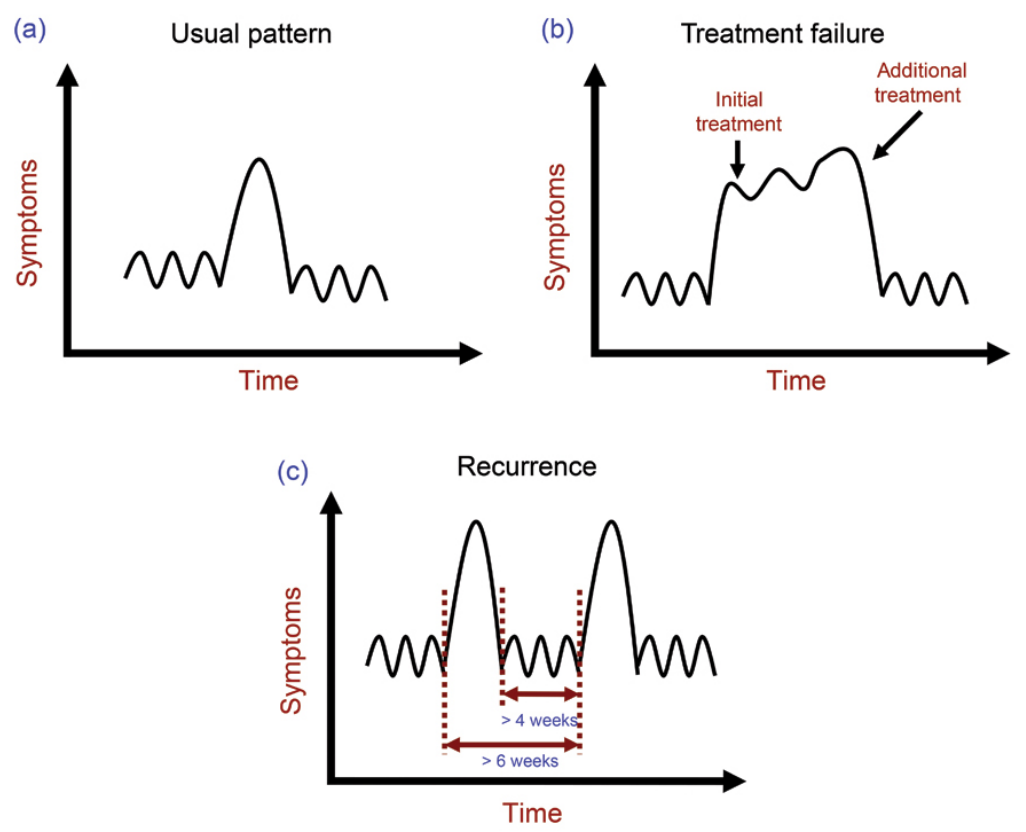

Proposed time-course patterns of COPD exacerbations: (a) usual pattern, (b) treatment failure (c) recurrence. For further explanations, see text. Reproduced with permission from Informa Healthcare, copyright (@2010, Informa Healthcare. ${ }^{25}$ exacerbation. Other symptoms, such as cough, have been poorly studied during exacerbations and systemic features, such as lethargy and fatigue, are not routinely assessed.

Finally, cardiovascular diseases are highly prevalent among patients with COPD. ${ }^{33}$ Recent research has begun to explore the possibility that occult cardiac disease may also play a role in the pathogenesis of COPD exacerbations. For instance, cardiac troponin has been shown to be frequently elevated in COPD exacerbations and is correlated with mortality among hospitalized patients. ${ }^{34}$ In this context, it is worth noting that Garcia-Aymerich et $\mathrm{al}^{35}$ used cluster analysis in a cohort of 342 patients hospitalized for the first time because of a COPD exacerbation and identified 3 groups of patients with different clinical, functional, imaging, and, more importantly, outcomes during a 4-year follow-up: Group 1 $(\mathrm{n}=126,37 \%)$ was labeled as severe respiratory $C O P D$ because they were characterized by severe airflow limitation (mean $\mathrm{FEV}_{1} 38 \%$ predicted) and extensive emphysema on computed tomography (CT). Group $2(\mathrm{n}=125,37 \%)$ was labeled as moderate respiratory COPD because they showed investigated the effects of experimental rhinovirus infection in 13 COPD patients and in 13 smokers with normal spirometry. They found that following rhinovirus infection, COPD patients developed more lower respiratory symptoms, more airflow limitation, and more systemic and airway inflammation than controls, thus providing circumstantial support for respiratory infections as a driver of exacerbations in COPD. Yet, recent research has also shown that not all exacerbations can be related to an infectious agent. Bafadhel et $\mathrm{al}^{31}$ studied 182 exacerbations in 145 patients and reported that bacteria and viruses could be isolated in 55\% and $29 \%$, respectively of all exacerbations but, importantly, not in all of them. These authors proposed that exacerbations may be subdivided into 4 distinct clusters: bacterial, viral, eosinophilic, and pauci-inflammatory (Figure 2 ) and suggested that sputum interleukin (IL) $-1 \beta$, serum CXCL10, and peripheral eosinophils could serve as diagnostic biomarkers for bacteria-, virus-, or eosinophil-associated exacerbations, respectively. ${ }^{31}$

Fourth, the symptoms of exacerbations include increased breathlessness, sputum volume, and sputum purulence as key features, ${ }^{32}$ but they do not always occur together and may develop at different times during the

\section{Figure 2.}

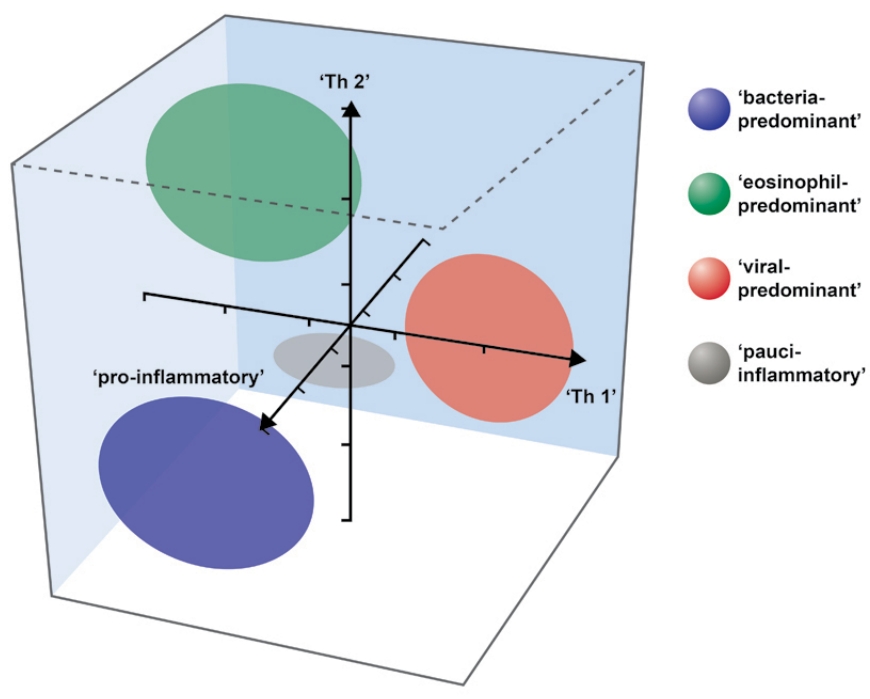

Three-dimensional, proportional ellipsoids representation of 4 clusters identified in patients with COPD exacerbations. For further explanations, see text. Reproduced from American Journal of Respiratory and Critical Care Medicine with permission. ${ }^{31}$

milder airflow limitation (mean $\mathrm{FEV}_{1} 63 \%$ predicted), but had similar emphysema characteristics compared to Group 1. Group 3 (n=91, 27\%) was labeled systemic 
COPD because they combined a milder airflow limitation $\left(\mathrm{FEV}_{1} 58 \%\right.$ predicted) with a high proportion of obesity, cardiovascular disorders, diabetes, and systemic inflammation, but no emphysema on CT. Importantly, during follow-up, Group 1 had more frequent hospitalizations due to COPD (hazard ratio $[\mathrm{HR}]=3.28, \mathrm{p}<0.001)$ and higher all cause mortality ( $\mathrm{HR}=2.36, \mathrm{p}=0.018$ ) than the other 2 groups, whereas Group 3 had more admissions due to cardiovascular disease ( $\mathrm{HR}=2.87$, $\mathrm{p}=0.014$ ) (Figure 3).

The results of this important study raise several important questions. First, how can it be that patients in Group 1 (with severe respiratory COPD) had not required hospitalization earlier during the course of their disease? Was it because they were poor perceivers, as discussed above, or just had no prior severe episodes? Second, these data provide clear evidence of heterogeneity among episodes of exacerbation and/or among individual patients suffering an exacerbation of COPD, as mentioned by the authors. Third, some exacerbations of COPD may actually represent exacerbation of symptoms in patients with COPD due to worsening of other less apparent, but frequent, comorbid diseases, such as heart failure. ${ }^{36}$ These questions deserve specific research if we are to understand, prevent, and treat these important events better and in a more effective manner.

\section{Known Risk Factors for Future Exacerbations}

The risk of exacerbations varies greatly among patients. For instance, results from the Evaluation of COPD Longitudinally to Identify Predictive Surrogate Endpoints (ECLIPSE) study showed that of the 2138 patients studied, $24 \%$ did not experience exacerbations during the 3 years of follow-up, $47 \%$ experienced $\geq 1$ exacerbation per year, and $29 \%$ experienced $\geq 2$ exacerbations. ${ }^{8}$ However, these figures cannot be used as standards since there are several aspects that might

\section{Figure 3.}

Panel A: Heat-map of the different COPD dimensions that characterize the 3 groups identified in the analysis. Group 1 was characterized by severe airflow limitation and worse performance in most of the respiratory domains of the disease. Group 2 combined milder airflow limitation with emphysema. Group 3 showed milder airflow limitation and a high proportion of groups of patients with COPD. For further explanations, see text. Reproduced from Thorax with permission from BMJ Publishing Group, Ltd. ${ }^{35}$
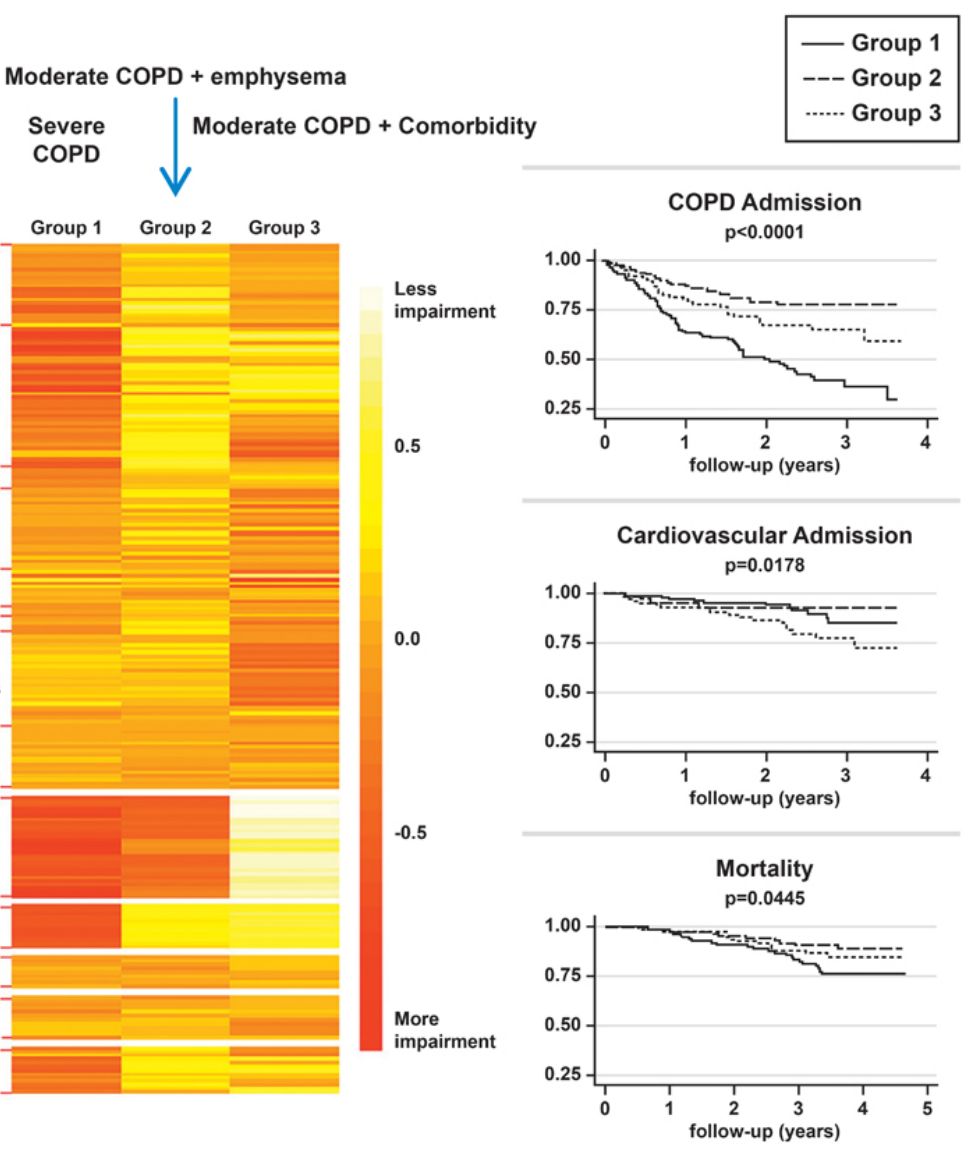


\section{Table 1. Risk Factors for COPD Exacerbations}

\section{Risk Factor}

\section{Previous}

Exacerbations

Older Age

\section{Details of Relationship}

Reference

Results from ECLIPSE indicated that the major determinant of frequent exacerbations in all GOLD stages 8 of COPD severity was a history of exacerbations.

Age $>65$ years was a significant risk factor for exacerbations ( $p=0.012$ versus individuals $\leq 65$ years old) in a cohort of 551 patients with COPD.

Exacerbation rate increased with COPD severity in ECLIPSE. In the first year of follow-up, it was 0.85 for patients with GOLD stage II COPD, 1.34 for patients with stage IIICOPD, and 2.00 for patients with stage IVdisease. Overall, $22 \%$ of patients with stage II disease, $33 \%$ with stage IIIdisease, and $47 \%$ with stage IVCOPD had frequent exacerbations ( $\geq 2$ in the first year of follow-up).

\section{Severity of \\ Airflow \\ Limitation}

Combined analysis of results from 37 studies indicated that event-based exacerbation frequencies per GOLD stage were 0.82 for mild, 1.17 for moderate, 1.61 for severe, and 2.10 for very severe COPD. Annual symptom-based frequencies were $1.15,1.44,1.76$, and 2.09 , respectively. For severe exacerbations (requiring hospital admission) annual frequencies were $0.11,0.16,0.22$, and 0.28 , respectively.

Lower $\mathrm{FEV}_{1}$ \% predicted was associated with increased risk for an exacerbation in a study of 1829 patients with moderate-to-severe COPD $(p<0.001)$.

Results from a cohort of 120 patients with mild-to-very severe COPD indicated that the relationship between the risk for moderate or severe exacerbations and BODE index score was an odds ratio of 2.08 over 1 year of follow-up.

\section{High BODE Index}

A 1-year retrospective study of 76 patients with a total of 178 exacerbations showed that exacerbation frequency was significantly correlated with BODE index score ( $\mathrm{p}=0.002)$.

An 8-year follow-up of 275 COPD patients indicated that the mean times to a first exacerbation and a first COPD-related emergency department visit were each inversely related to worsening BODE score (based on quartiles).

A study of 70 patients who were followed for 1 year showed that daily cough ( $p=0.018)$ and daily cough and sputum $(\mathrm{p}=0.009)$ were each associated with increased exacerbation frequency.

A study of 1829 patients with moderate-to-severe COPD indicated that productive cough was associated with increased risk for an exacerbation ( $\mathrm{p}=0.003)$.

A cross-sectional study of 433 patients with COPD indicated that those with chronic cough and sputum production had significantly increased risk for total, moderate, and severe exacerbations $(p<0.0001)$.

\section{Chronic} Bronchitis

A study that included 759 patients with COPD indicated that those with chronic bronchitis had more frequent exacerbations than those without such symptoms.

A case-control study of 192 patients with GOLD stage III or IV COPD who were frequent exacerbators ( $\geq 2$ moderate-to-severe exacerbations per year) versus 153 non-exacerbators indicated the modified Medical Research Council dyspnea score and $\mathrm{FEF}_{25-75} \%$ predicted were significant predictors of frequent exacerbator status $(\mathrm{p}<0.05)$.

A study of 70 patients with COPD indicated that total score and each of the scales from the SGRQ were significantly correlated with risk for exacerbations (all $\mathrm{p}<0.05$ )

Poor

Health-

Status

Results from 121 patients with moderate-to-severe COPD indicated that each unit increase in the total SGRQ score was associated with a 3\% higher risk of being a frequent exacerbator $(p=0.047)$.

Results from a study of 161 patients indicated that frequent exacerbators had significantly higher baseline CAT scores than infrequent exacerbators $(\mathrm{p}=0.025){ }^{\mathrm{a}}$ 
Comorbid cardiovascular disease was a significant predictor of hospitalization for an exacerbation in a cohort of 1829 patients with moderate-to-severe COPD who were followed for 6 months $(p<0.001)$.

Assessment of 106 patients with COPD (29 with metabolic syndrome and 77 without this condition) followed for 12 months indicated that the mean exacerbation frequency was 2.4 in those with metabolic syndrome versus 0.68 for those without this condition $(p<0.001)$.

Presence $\quad$ Results from a prospective cohort study in 491 patients with stable COPD indicated that probable of depression was associated with an increased risk of symptom-based exacerbations, event-based

Systemic Disease/ Comorbidities exacerbations, and hospitalization due to exacerbations versus no depression.

A study of 110 patients with stable COPD indicated that those with psychiatric disorders had significantly increased risk for exacerbations $(p=0.003)$.

A study of 169 patients indicated that frequent exacerbators had a significantly higher median baseline depression score than infrequent exacerbators $(p=0.03)$.

A study of 1755 COPD patients, 297 smokers with normal spirometry, and 202 non-smoker controls that were followed-up for 3 years indicated that evidence of systemic inflammation (elevated peripheral WBC count, CRP, IL-6, IL-8, fibrinogen and TNF-a) was associated with increased exacerbation frequency $(p<0.001)$.

\section{Bacterial Colonization of Lower Airways}

\begin{tabular}{l} 
Bronchial \\
Wall \\
Thickness \\
\hline Emphysema \\
\hline Gastroesophageal \\
Reflux
\end{tabular}

\section{Increased}

Pulmonary

Artery

Diameter
Results from 29 patients with COPD indicated that lower airway colonization (most common pathogens were Haemophilus influenzae, Streptococcus pneumoniae, H parainfluenzae, Moraxella catarrhalis, and Pseudomonas aeruginosa) was associated with increased exacerbation frequency ( $\mathrm{p}=0.023)$.

A study of 1002 patients with COPD indicated that each $1 \mathrm{~mm}$ increase in bronchial wall thickness measured from CT scans was associated with a 1.84-fold increase in annual exacerbation rate $(p=0.004)$

For patients with $35 \%$ or greater total emphysema, each $5 \%$ increase in emphysema was associated with a 1.18 -fold increase in this rate $(\mathrm{p}=0.047)$.

Results from ECLIPSE indicated that more frequent exacerbations were associated with a history of gastroesophageal reflux disease.

Pulmonary artery enlargement (a PA:A ratio of $>1$ ), as detected by $\mathrm{CT}$, was associated with severe exacerbations of COPD.

$\mathrm{BODE}=$ Body mass index-airflow Obstruction - Dyspnea-Exercise capacity, $\mathrm{CRP}=\mathrm{C}$-reactive protein, ECLIPSE $=$ Evaluation of COPD Longitudinally to Identify Predictive Surrogate Endpoints, FEF $25-75$ = Forced Expiratory Flow Between $25 \%$ and $75 \%$ of Forced Vital Capacity, FEV 1 = forced expiratory volume in 1 second, IL = interleukin, SGRQ = St George's Respiratory Questionnaire, $\mathrm{TNF}=$ tumor necrosis factor, $\mathrm{WBC}=$ white blood cell; $\mathrm{CAT}=\mathrm{COPD}$ Assessment Test

${ }^{a}$ Results from clinical studies have shown that the minimum clinically important difference for CAT score ranges from -1.6 to -2.0. ${ }^{41,82,131}$ Changes of -1.3 and -3.8 were reported by patients who indicated that they felt a little better or much better, respectively, after pulmonary rehabilitation. ${ }^{131}$ Exacerbations increase the CAT score by $+5.2 .^{41}$ 
airway colonization, ${ }^{53}$ airway wall thickening demonstrated by computed tomography (CT), ${ }^{54}$ gastroesophageal reflux 8 and pulmonary artery enlargement detected by $\mathrm{CT}^{55}$ Finally, female gender has been noted to be associated with increased risk of exacerbations in several recent large clinical trials 56,57 although it is unclear whether this represents a difference in reporting or disease biology.

Furthermore, it has been suggested that exacerbations beget exacerbations. A large study carried out by Suissa et al using a Canadian Pharmacy database that included 73,106 patients hospitalized for the first time for COPD and followed for up to 17 years showed that the risk of a subsequent severe exacerbation increased 3-fold after the second exacerbation requiring hospitalization, and 24-fold after the 10th exacerbation as compared to after the first hospitalization for an exacerbation (Figure 4).

\section{Figure 4.}

\section{Risk of}

\section{Severe exacerbation}
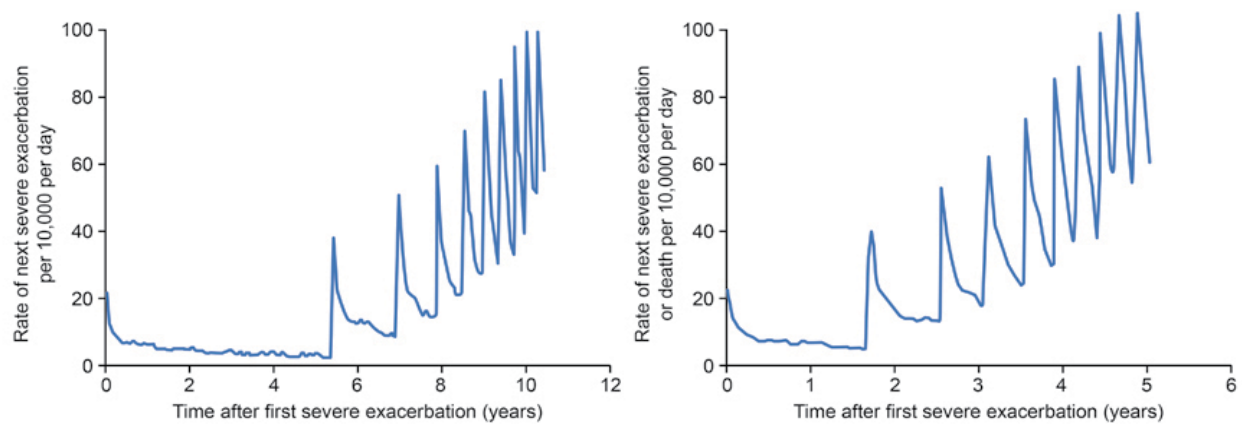

Hazard function of successive hospitalized COPD exacerbations (per 10,000 per day) from the time of their first ever hospitalization for a COPD exacerbation over the follow-up period. For further explanations, see text. Reproduced from Thorax with permission from BMJ Publishing Group, Ltd. ${ }^{58}$

From these observations, Suissa et al suggested that the course of COPD has 2 phases after the first hospitalized exacerbation. The first is a less than 2-year period of stable risk until the second hospitalized exacerbation or death. After the second hospitalized exacerbation, severe exacerbations recur progressively sooner after each subsequent severe exacerbation and the mortality rate rises with every new exacerbation. Thus, there is a window of opportunity during the stable phase after the first hospitalization to intervene and potentially prevent a subsequent severe exacerbation. ${ }^{58}$ In keeping with this view, it is now recognized that COPD exacerbations cluster and that having an event makes a patient more susceptible to another event within an 8 -week period. ${ }^{26}$
Patients who are frequent exacerbators are also more likely to have a history of recurrent events. ${ }^{26}$ However, when the gap between episodes is long, the progression of COPD itself may sensitize the patient to episodes that would have appeared minor earlier in the disease. In any case, recurrent hospitalization for exacerbations is a common and serious problem in $\mathrm{COPD}^{59,60}$ and reducing the risk for exacerbation-associated rehospitalization is thus an important treatment goal.

\section{Reducing the Risk of Future Exacerbations}

Decreasing or, ideally, abolishing exacerbations is an important goal in COPD. ${ }^{61}$ Over the past 2 decades, several new approaches to exacerbation risk reduction have emerged. Table 2 summarizes the efficacy of different therapeutic options in decreasing COPD exacerbations and the following sections discuss these options in detail. However, 3 notes of caution are worth emphasizing in order to interpret published findings.

First, when considering the clinical trials and meta-analyses described in the following sections, it is important to emphasize that a number of factors can influence results reported, including definition and recording of exacerbations, the baseline exacerbation rate for the patient, and study duration. Thus, while comparisons of different interventions within a given wellcontrolled trial provide useful information about relative efficacy of treatments, use of results from different studies to compare treatments should be viewed with caution.

Second, multiple approaches have been employed to capture exacerbations in clinical trials. These include the occurrence of "harder" events, such as requirement for specific changes in medication (e.g., administration of systemic corticosteroids and/or antibiotics) and hospitalization ${ }^{62}$; use of symptom diary cards, ${ }^{14,63}$ and specific questionnaires, such as the COPD Assessment Test $(\mathrm{CAT})^{41}$ and the Exacerbations of Chronic Pulmonary Disease Tool (EXACT). ${ }^{64}$ It has been noted that the use of different methods to define and analyze exacerbations can result in biased estimates of 
Table 2. Efficacy of Different Approaches to Decreasing Risk for Exacerbations

\begin{tabular}{|c|c|c|c|}
\hline \multicolumn{3}{|c|}{ Efficacy } & References \\
\hline \multicolumn{4}{|c|}{ Non-pharmacologic Interventions } \\
\hline Smoking Cessation & Supported & Large-scale observational study & 66 \\
\hline Pulmonary Rehabilitation & Supported & Small-scale clinical studies & 68,69 \\
\hline $\begin{array}{l}\text { Vaccination Against } \\
\text { Pneumococcal and } \\
\text { Influenza Virus Infection }\end{array}$ & Very strongly supported & Multiple clinical trials and meta-analyses & $70-74$ \\
\hline \multicolumn{4}{|l|}{ Pharmacotherapy } \\
\hline LABA & Very strongly supported & Meta-analyses and multiple clinical trials & 13,76 \\
\hline LAMA & Very strongly supported & Meta-analyses and multiple clinical trials & $\begin{array}{l}57,79,80, \\
82,83\end{array}$ \\
\hline $\begin{array}{l}\text { LABA + LAMA } \\
\text { vs. Monotherapy }\end{array}$ & $\begin{array}{l}\text { Supported for LABA + LAMA } \\
\text { vs LAMA monotherapy }\end{array}$ & Clinical trial & 132 \\
\hline ICS Monotherapy & Supported & $\begin{array}{l}\text { Meta-analysis, benefit limited to patients } \\
\text { with FEV } 1<50 \%\end{array}$ & 91 \\
\hline $\begin{array}{l}\text { ICS + LABA vs ICS or } \\
\text { LABA monotherapy }\end{array}$ & Very strongly supported & Multiple clinical trials & 56,94 \\
\hline $\begin{array}{l}\text { Triple Combination } \\
\text { Therapy vs. Components }\end{array}$ & Variable results & $\begin{array}{l}\text { Small-scale clinical trials provide conflicting } \\
\text { results; meta-analysis indicates no significant } \\
\text { benefit; large-scale observational study } \\
\text { supports }\end{array}$ & $\begin{array}{l}102-105 \\
133\end{array}$ \\
\hline \multicolumn{4}{|l|}{ Systemic Treatments } \\
\hline Roflumilast & $\begin{array}{l}\text { Very strongly supported as } \\
\text { add-on treatment to } \\
\text { bronchodilators }\end{array}$ & $\begin{array}{l}\text { Multiple large-scale clinical trials and meta- } \\
\text { analysis }\end{array}$ & $106-109$ \\
\hline Macrolides/Quinolones & Strongly supported & Supported by large-scale clinical trials & 116,117 \\
\hline Statins & Supported & $\begin{array}{l}\text { Supported by multiple observational studies, } \\
\text { but no controlled trials to date }\end{array}$ & 121,122 \\
\hline
\end{tabular}

ICS = inhaled corticosteroid, LABA = long-acting ß2-agonist LAMA = long-acting muscarinic antagonist treatment effects, so it has been suggested that trials should report time-weighted intention-to-treat analyses with adjustments for between-participant variation in COPD exacerbations. ${ }^{65}$

Third and finally, it is also of note that none of the therapeutic interventions discussed below fully prevents exacerbations. On average, most reduce their incidence by $15 \%-30 \%$, so a large number of exacerbations are not prevented by current therapies. Again, however, some words of caution are necessary. First, the above caveats about the definition of exacerbations and differentiation from worsening of the same episode or recurrent episodes (Figure 1) apply here. Second, data are average results observed in large cohorts. Whether or not this occurs in an individual patient remains a different issue. In fact, Hurst et al showed that, in ECLIPSE, a significant number of individual patients switch from suffering frequent exacerbations $(\geq 2$ / year) to 1 or less (and vice versa). ${ }^{8}$ Further, the extent to which the reduction of exacerbation rates observed in clinical trials can be directly extrapolated to the real world, where compliance with treatment is likely lower, is unclear. Finally, until we have a comprehensive understanding of the pathobiology of exacerbations (infection, spontaneous burst of inflammation, bronchospasm, others) it will be difficult to define a therapeutic strategy, including the effective treatment of all the trigger factors, that achieves an exacerbation-free COPD goal. ${ }^{61}$

\section{Non-pharmacologic Interventions Smoking Cessation}

Stopping smoking decreases the risk for exacerbations. In a cohort of 23,971 United States military veterans, being an ex-smoker rather than a current smoker significantly reduced the risk of COPD exacerbations even after adjustment for age, comorbidity, markers of COPD severity and socioeconomic status (adjusted $\mathrm{HR}=0.78,95 \%$ confidence interval $(\mathrm{CI})=0.75-0.87){ }^{66} \quad$ The exact mechanism is unknown although it should be noted that nicotine is a growth factor for non-typeable Haemophilus influenza, which is thought to be a major bacterial pathogen in at least some exacerbations. ${ }^{67}$

\section{Pulmonary Rehabilitation}

Meta-analysis of results from 9 relatively small trials that included 432 patients indicated that pulmonary rehabilitation significantly decreased future hospital admissions $(\mathrm{p}<0.05) .{ }^{68}$ Results from an additional controlled trial of 60 patients admitted to the hospital for an exacerbation also indicated that post-discharge pulmonary rehabilitation significantly decreased the risk for subsequent exacerbations $(p=0.02) .{ }^{69}$ These benefits may reflect a resetting of the symptom threshold and/or the improvement of the general physical condition of the patient.

\section{Vaccination}

Results from several studies and meta-analyses have demonstrated that vaccination against influenza virus (and possibly pneumococcocus) decreases the risk for 
exacerbation in patients with COPD. ${ }^{70-74}$ presumably by enhancing the immunity against such organisms.

\section{Bronchodilator Treatment}

Long-acting bronchodilator treatment is the cornerstone for treatment of stable COPD ${ }^{75}$ and it significantly decreases the risk for exacerbations. ${ }^{76-78}$ A metaanalysis of results from 9 clinical trials that compared tiotropium (a long-acting muscarinic antagonist [LAMA]) with placebo, ipratropium, or salmeterol (a long-acting $\beta 2$-agonist [LABA]) showed that tiotropium reduced the number of exacerbations per patient-year by 0.31 (95\% CI=0.46-0.17) compared to placebo, and by 0.23 (95\% CI=0.31-0.15) compared to ipratropium. The number of hospitalizations was reduced by 0.04 (95\% CI $=0.08-0.01$ ) per patient-year compared to placebo and by 0.06 (95\% CI $=-0.09$ to -0.03$)$ per patient-year compared to ipratropium. ${ }^{79}$ A significant difference in exacerbation frequency between tiotropium and salmeterol also was reported $(-0.16,95 \% \mathrm{CI}=-0.29$ to -0.03) based on the results from a single study included in the analysis. ${ }^{79}$ Results from another meta-analysis of 9 studies compared salmeterol with placebo/usual care ${ }^{76}$ and indicated that salmeterol significantly decreased the risk for moderate (requiring the use of additional oral corticosteroids and/or antibiotics) or severe (requiring hospitalization) exacerbations by $22 \%$ over 12 months $(p<0.0001)$. The benefit of salmeterol was maintained regardless of the severity of airflow limitation, smoking history, or current therapy. ${ }^{76}$

A 1-year head-to-head comparison of tiotropium and salmeterol in 7376 patients with COPD showed significant superiority of tiotropium over salmeterol in decreasing risk for exacerbations. ${ }^{80}$ This occurred whether the effect was defined as an increase in, or new onset of, more than 1 symptom of COPD, with at least 1 symptom lasting 3 days or more $(p<0.001)$, increased time to first exacerbation requiring hospitalization $(p<0.001)$, or reduced frequency of annual exacerbations leading the patient's attending physician to initiate treatment with systemic glucocorticoids, antibiotics, or both $(\mathrm{p}=0.002)$, or exacerbations requiring hospitalization $(p<0.001)$. Results from a 26-week comparison of tiotropium with indacaterol (a more recently developed LABA) indicated no significant difference between treatments in decreasing risk for exacerbations, defined as onset or worsening of one or more respiratory symptoms for 3 or more consecutive days, plus new treatment (e.g., systemic steroids, antibiotics, oxygen) and/or hospitalization or an emergency department visit. ${ }^{13}$ Furthermore, a recent comparison of these 2 agents indicated that indacaterol was comparable to tiotropium in terms of annualized exacerbation rates ( 0.79 versus 0.61 ; ratio 1.29 , one-sided $97.5 \%$ CI upper limit 1.44 ). In this study, an exacerbation was defined as worsening for $\geq 2$ consecutive days for $\geq 2$ of the major symptoms (dyspnea, sputum volume, or sputum purulence) or worsening of any 1 major symptom together with any 1 minor symptom (sore throat, colds, fever without other cause, increased cough, or increased wheeze). ${ }^{81}$

Finally, 2 more recently developed LAMAs, aclidinium and glycopyrronium bromide, have also been shown to significantly decrease the frequency of exacerbations (defined as worsening of 2 or more major symptoms for at least 2 consecutive days or worsening of any 1 major symptom together with any minor symptom for at least 2 consecutive days) in patients with COPD versus placebo. ${ }^{82,83}$

In summary, available evidence clearly indicates that long-acting bronchodilators significantly reduce the occurrence of exacerbations in patients with COPD. This may represent the improvements in baseline lung function thereby resetting the symptom threshold or the prevention of episodes in which acute bronchoconstriction plays a role. An important question that remains to be definitively answered is whether the combination of a LABA and a LAMA is significantly superior to monotherapy in decreasing exacerbations. Recent results have indeed indicated that a LABA-LAMA combination was significantly superior to LAMA alone in decreasing the rate of moderate to severe exacerbations. ${ }^{84}$ However, it should be noted that results reflect group data and it remains unclear whether the effects of LABA plus LAMA are additive in a given patient or reflect benefit to different individuals or even episodes with different characteristics.

Finally, the effects of methylxanthines in preventing exacerbations are unclear, since according to the GOLD recommendations, treatment with theophylline is not recommended unless other long-term treatment bronchodilators are unavailable or unaffordable. ${ }^{1}$ Yet, there is some evidence that these agents may enhance the anti-inflammatory effects of steroid treatment during exacerbations. ${ }^{85}$ Their potential role when combined with inhaled steroid treatment in preventing COPD exacerbations merits further research. 


\section{Inhaled Corticosteroids}

Since an enhanced and persistent inflammatory response to inhaled gases and particles is believed to be a key pathogenic mechanism of COPD, ${ }^{1}$ and COPD exacerbations appear to be often characterized by an inflammatory burst, the use of anti-inflammatory therapy to prevent (and treat) exacerbations is a rational treatment option. 1,75

Many different studies have explored the efficacy (and safety) of inhaled corticosteroids (ICS) to reduce exacerbations in patients with COPD, either alone or in combination with LABA or LABA plus LAMA (socalled, triple therapy), and these are reviewed below. It should be noted, however, that the use of ICS in COPD is controversial. In vitro, ICS has limited efficacy in suppressing inflammation in cells harvested from COPD patients, an effect that seems to be related to a marked reduction in histone deacetylase-2, the nuclear enzyme required by corticosteroids to de-activate inflammatory genes. ${ }^{86-88}$ In addition, high doses of ICS may have deleterious effects on bone metabolism and also appear to increase the risk of pneumonia in COPD. ${ }^{89,90}$

\section{Inhaled Corticosteroid Monotherapy}

A meta-analysis of 11 studies that included 8164 patients showed that ICS alone significantly decreased the risk for exacerbations versus placebo (relative risk $=0.82, \mathrm{p}<0.05$ based on 95\% CI). ${ }^{91}$ However because the use of bronchodilator therapy is mandatory in COPD, (at variance with patients with asthma) ICS as monotherapy is not recommended in COPD. ${ }^{92}$

\section{Inhaled Corticosteroids Plus Long-acting $\beta-2$ Agonist}

There is clear evidence that the combination of LABA with ICS is superior to LABA alone in decreasing exacerbations. The Towards a Revolution in COPD Health (TORCH) study was a randomized, double-blind trial that compared salmeterol $(50 \mu \mathrm{g})$ plus fluticasone propionate $(500 \mu \mathrm{g})$ versus placebo, salmeterol alone, or fluticasone propionate alone for a period of 3 years in 6112 patients with COPD and $\mathrm{FEV}_{1}<60 \%$ predicted. Study results showed that the combination regimen was significantly superior to placebo $(\mathrm{p}<0.001)$, fluticasone $(p=0.02)$, and salmeterol $(p=0.002)$ for decreasing the rate of exacerbations requiring treatment with antibiotics, systemic corticosteroids, or a combination of these interventions $(p<0.001, p=0.02$, and $p<0.001$, respectively). Of interest, combination therapy was significantly superior to placebo and ICS alone, but not to salmeterol, for decreasing the rate of exacerbations requiring hospitalization. ${ }^{56}$ Recent data have confirmed that exacerbation prevention is enhanced by adding ICS to a LABA even when these drugs are given once daily and in the absence of any apparent effect on lung function, at least in one of the trials reported. ${ }^{93}$ However, patients receiving fluticasone (alone or in combination with salmeterol) had an increased risk of pneumonia.

The efficacy of another ICS/LABA combination, budesonide/formoterol, was compared with placebo, budesonide, and formoterol in 812 patients with moderate-to-severe COPD (mean $\mathrm{FEV}_{1} 36 \%$ predicted) in a 12-month, randomized, double-blind, placebocontrolled, parallel-group study. Patients received 2 inhalations twice daily of budesonide/formoterol (160/4.5mg), budesonide (200mg), formoterol (4.5mg), or placebo. The combination of budesonide/ formoterol significantly decreased exacerbations compared to placebo $(\mathrm{p}=0.035)$ and formoterol alone $(\mathrm{p}=0.043) .{ }^{94}$ These results were reproduced by Calverley et al. ${ }^{95}$ Again the added benefit of ICS may reflect prevention of a different exacerbation variant, perhaps those associated with eosinophilic inflammation. ${ }^{96,97}$ Some studies suggest that the risk of pneumonia is lower in patients treated with budesonide than with fluticasone. ${ }^{98,99}$

\section{Inhaled Corticosteroids Plus Long-acting Muscarinic Antagonists}

The effects of ICS plus a LAMA (tiotropium) have been evaluated for outcomes, including pulmonary function, symptoms, and health-related quality of life, 100, $101 \mathrm{but}$ there is no published information regarding the benefit of this combination versus LAMA monotherapy for decreasing exacerbations. However, the Prevention of Exacerbations with Tiotropium in COPD (POET-COPD) study showed that once-daily treatment with tiotropium was more effective than twice-daily salmeterol (with or without ICS) in preventing exacerbations ${ }^{80}$ suggesting ICS may provide little additional benefit to LAMA.

\section{Triple Therapy}

Studies that have assessed the effects of LABA plus ICS plus tiotropium on the risk of future exacerbations have produced mixed results. Those showing evidence in favor of the use of triple therapy include the following: (1)A study of 126 patients showed that the combination of tiotropium plus salmeterol/fluticasone resulted in significantly fewer exacerbations than either tiotropium 
or salmeterol/fluticasone over 12 months of followup $(\mathrm{p}<0.01) .{ }^{102}$ (2)A 12-week, randomized, doubleblind, parallel-group, multicenter study that included 660 patients who received tiotropium plus either budesonide/formoterol or placebo twice daily, showed that triple therapy significantly decreased the risk for severe exacerbations $(p<0.001)$ and the frequency of hospitalizations and emergency department visits ( $\mathrm{p}=0.011)$ versus tiotropium alone. ${ }^{103}$ This latter study, however, lasted only 12 weeks, so results should be viewed with caution since it has been recommended that studies investigating COPD exacerbations should have a duration of at least 12 months because of seasonal variation in exacerbation frequency. ${ }^{63}$ (3) A recent observational study that included results from 3333 Medicare enrollees also showed that triple therapy with fluticasone, tiotropium, and salmeterol was significantly superior to tiotropium alone in reducing the risk for moderate exacerbations ( $\mathrm{HR}=0.772,95 \%$ $\mathrm{CI}=0.641-0.930)$ and any exacerbation (HR=0.763, 95\% CI=0.646-0.949). However it should be noted that all of these studies assume that double combination is superior to monotherapy.

The ideal study should be triple therapy versus each component of the combination and an arm comprised of ICS/LABA and this has been approximated by several trials. (1)A Canadian study of 449 patients with moderate or severe COPD reported that the addition of either salmeterol, or salmeterol plus fluticasone to tiotropium did not significantly decrease the frequency of exacerbations versus tiotropium alone, although it did significantly decrease the risk for exacerbations requiring hospitalization (incidence rate ratio $=0.53$, $\mathrm{p}<0.05$ based on $95 \% \mathrm{CI}) .{ }^{104}$ However, this study had an excess of dropouts and was not adequately powered for exacerbations. (2)Results from a meta-analysis of 20 trials (including 6803 patients) that compared tiotropium alone versus tiotropium plus a LABA or tiotropium plus a LABA and ICS, showed no additional benefit of any of the combinations in decreasing exacerbations compared to tiotropium monotherapy. ${ }^{105}$

\section{Roflumilast}

Roflumilast, a phosphodiesterase 4 inhibitor, is a novel non-steroidal anti-inflammatory drug that is administered orally for the treatment of COPD. Several studies have evaluated the additive effects of roflumilast on the frequency of exacerbations in patients with COPD. Two identical 12-month studies compared roflumilast
( $n=1537)$ versus placebo ( $n=1554$ ) (on top of usual care) in patients with severe COPD, chronic bronchitis, and a history of at least one exacerbation in the previous year. Results showed that the rate of moderate-tosevere exacerbations was significantly reduced by $17 \%$ with roflumilast $(\mathrm{p}<0.0003) .{ }^{106}$ The greatest effect (22\% reduction in moderate to severe exacerbations; $\mathrm{p}=0.0017$ ) was seen in patients with a history of frequent exacerbations ( $\geq 2$ per year). ${ }^{107}$ In addition, a pre-specified pooled subgroup analysis showed that roflumilast reduced moderate-to-severe exacerbations when added to LABA by $21 \%(\mathrm{p}=0.0011) .{ }^{107}$ Addition of roflumilast to salmeterol in 933 patients with COPD for 24 weeks significantly increased time to first exacerbation $(p=0.0067)$ and decreased the proportion of patients with an exacerbation $(p=0.0419)$ versus addition of placebo. ${ }^{108}$ Addition of roflumilast to tiotropium in 743 patients also significantly increased the time to first exacerbation ( $p=0.0264)$ and decreased the proportion of patients with an exacerbation $(p=0.0169)$ versus addition of placebo. ${ }^{108}$

Several post-hoc analyses provided further relevant clinical information: (1)The effect of roflumilast persisted even in the presence of concomitant treatment with ICS. ${ }^{109}$ (2)As reported in abstract form, roflumilast significantly decreased hospitalization due to severe exacerbations ${ }^{110}$ and that of moderate-to-severe exacerbations when added to tiotropium in highly symptomatic patients (modified MRC scale score $\geq 2$ at baseline). ${ }^{111}$ (3)Among frequent exacerbators treated with roflumilast, $32.0 \%$ still had frequent exacerbations after 1 year of treatment, as compared to $40.8 \%$ of placebo-treated patients $(p=0.0148) .{ }^{112}$ Conversely, $17.5 \%$ of infrequent exacerbators treated with roflumilast became frequent exacerbators at year 1 , versus $22.9 \%$ of those taking placebo $(p=0.0018) .{ }^{112}$ The beneficial effects of roflumilast were seen most clearly in COPD patients with the chronic bronchitis phenotype, suggesting that this is an important clinical biomarker for a responder group. Of note, a proportion of patients had to discontinue roflumilast mostly because of adverse gastrointestinal effects.

\section{Prophylactic Antibiotic Treatment}

Since bacterial airway colonization with potentially pathogenic organisms can occur in COPD, ${ }^{113}$ and this seems to relate to exacerbation risk, ${ }^{53,114}$ several studies have explored whether chronic antibiotic treatment can decrease exacerbation frequency. 


\section{Macrolides}

A study in 109 COPD outpatients showed that administration of erythromycin $250 \mathrm{mg}$ twice daily significantly decreased the frequency and duration of exacerbations over 1 year $(\mathrm{p}=0.003) .{ }^{115}$ Similarly, a 1-year study of 1142 COPD patients who received azithromycin at a dose of $250 \mathrm{mg} /$ day or placebo indicated that active treatment significantly decreased exacerbation frequency $(p=0.01) .{ }^{116}$ It remains uncertain whether the benefit reflects the antimicrobial or anti-inflammatory properties of macrolides. Further, development of antibiotic resistance is also a potential complication of long-term macrolide treatment. In the study carried out by Albert et al, ${ }^{116}$ cultures for susceptibility testing were available from $68 \%$ of the participants in the azithromycin group and $70 \%$ in the placebo group who were not colonized with selected respiratory pathogens at the time of enrollment but who became colonized during the course of the study $(p=0.76)$. In these patients, the incidences of resistance to macrolides were $81 \%$ and $41 \%$, respectively $(p<0.001)$. Finally, this study also showed that audiogramconfirmed hearing deficits occurred significantly more often with azithromycin than placebo in these patients $(p=0.04)^{116}$ suggesting such an approach should be considered with caution.

\section{Quinolones}

A study of 1157 COPD patients who received moxifloxacin or placebo once daily for 5 days, every 8 weeks, for a total of 6 cycles showed that antibiotic administration significantly decreased exacerbations in the per-protocol population $(p=0.046)$, but not in the intent-to-treat population $(\mathrm{p}=0.059) .{ }^{117}$ Furthermore, administration of a single course of moxifloxacin treatment aimed at eradication of bronchial colonization did not significantly decrease exacerbations in a cohort of 119 stable patients with COPD. ${ }^{118}$ Thus, benefits of quinolones have not been proven although this may reflect failure to enrich the study population for patients colonized with bacteria and exacerbations thought to be of bacterial origin.

\section{Statins}

Statins inhibit the enzyme HMG-CoA reductase and are used in clinical practice to treat hypercholesterolemia. Statins also have significant anti-inflammatory effects, and epidemiologic studies have shown that administration of statins is associated with significantly decreased all-cause mortality in COPD patients. ${ }^{119,120}$ A retrospective study of 185 patients indicated those receiving statins had a significantly lower frequency of exacerbations than those who did not $(p<0.0001),{ }^{121}$ but such effects have not been evaluated in a prospective controlled trial. Likewise, a study that used the Taiwan National Health Insurance database and included 6252 patients with COPD also indicated that statin use significantly decreased the risk for exacerbations requiring hospitalization. ${ }^{122}$ However, it remains unknown whether these episodes reflect reduction in exacerbations of a cardiac nature.

\section{$\beta$-Blockers}

It is unclear if treatment with $\beta$-blockers decreases mortality in patients with exacerbations. On the one hand, results from 825 COPD patients admitted to the hospital with an exacerbation indicated that $\beta$-blocker use was associated with reduced mortality ( $\mathrm{OR}=0.39$, 95\% CI=0.14-0.99). ${ }^{123}$ On the other, however, a prospective national study of 2249 patients starting long-term oxygen therapy for COPD in Sweden indicated increased mortality for those receiving $\beta$-blockers (HR=1.19, 95\% CI=1.04-1.37, $\mathrm{p}=0.010) .{ }^{124}$ Thus, the benefits/harm may be patient phenotype dependent.

\section{Antioxidants}

Since COPD is associated with significant oxidative stress, the use of antioxidant agents have also been tested in these patients. ${ }^{125}$ Results, however, have been negative ${ }^{126}$ or arguably reflect a number of methodological flaws ${ }^{127}$ at prevention of exacerbations in patients with COPD.

\section{Targets for Future Research}

The studies reviewed above reveal a number of important knowns and unknowns related to COPD exacerbations. Given the importance of exacerbations in the natural history of the disease, the episodes are clear targets for future research. Among current knowns we would include: (1)the realization of the important impact that exacerbations have upon the natural course of the disease and the prognosis and well-being of COPD patients, (2)that multiple risk factors for exacerbations have been established; and (3)that results 
from multiple clinical trials have shown that currently available treatments for COPD can decrease, but not abolish exacerbations.

On the other hand, among current unknowns we would highlight as particularly relevant are the following: (1) Since COPD exacerbations are heterogeneous ${ }^{24,31}$ there is much more to be learned about the nature of these events and how they differ across the spectrum of patients with this disease (e.g., those with mild versus more severe COPD and those with different comorbidities). Objective outcome measures for detection and assessing severity of exacerbations are required, especially for clinical trials. EXACT is a novel instrument for the study of exacerbations. Available data suggests that when EXACT is used for detection of exacerbations, the relationship between these events and standard health care utilization is not very strong. However, EXACT is a good tool for the assessment of exacerbation severity and recovery. ${ }^{128}$ (2)We need to identify and validate reliable biomarker(s), both biochemical, clinical and physiological, to diagnose exacerbations precisely, differentiate among different types of exacerbations, guide preventive therapy, and establish the prognosis. (3)We need a defined approach for targeting therapies to prevent exacerbations based on their characteristics in a given patient and in different subgroups (i.e., phenotypes) of COPD, since effects of medication on exacerbation rate in different phenotypes have so far been disappointing. For instance, it was not possible to show that roflumilast had a greater effect on exacerbation rate in frequent exacerbators ${ }^{112}$ suggesting similar variability of episodes in both frequent and infrequent exacerbators. Similarly, the effects of salmeterol/fluticasone or tiotropium on exacerbation rates were similar in GOLD stages II, III and IV. (4)We need to understand the influence of comorbidities on the risk for and nature of exacerbations since improved management of these conditions decrease exacerbation risk. For instance, results from 1 study showed that in patients with both obstructive sleep apnea (OSA) and COPD (termed an overlap syndrome), treatment with continuous positive airway pressure (a standard therapy for OSA) decreased the risk for exacerbations requiring hospitalization. ${ }^{129}$ Much more research is therefore needed to determine whether better management of common COPD comorbidities, such as cardiovascular disease, can decrease the risk for exacerbations. (5)We need to understand whether persistent systemic inflammation is a cause or effect of increasing exacerbation risk. ${ }^{52}$ The effects of available anti-inflammatory therapies (ICS, roflumilast, statins, other) in this particular subgroup of patients deserve further study. (6)We need to understand why we are not able to completely prevent exacerbations, even when all available drugs are used in combination. This suggests that we are not targeting some unknown but important mechanism(s). (7)In addition to treatments designed to prevent exacerbations, the management of the acute episodes clearly needs improvement, since a significant proportion of patients require early hospital readmission and post exacerbation mortality is high.

Building on the current knowns will certainly allow the academic community to reduce the number of current unknowns and, with that, improve the treatment of patients suffering from COPD, not only because symptoms will be alleviated and their health-status improved today but, importantly, we will reduce the risk of undesired events tomorrow.

\section{Acknowledgements:}

This manuscript is the result of discussions at the Expert Leadership of COPDforum, a Takeda initiative that took place September 28, 2012, in Amsterdam, the Netherlands. The content of the manuscript was developed solely by the authors. The authors wish to acknowledge the medical writing and editorial support of Robert Rhoades, PhD, BoomCom, Inc., funded by Takeda. Takeda was given the opportunity to review the final version of the manuscript for accuracy of the data. However, consideration of any review comments remained at the full discretion of the authors. 


\section{References}

1. Vestbo J, Hurd SS, Agustí AG, et al. Global strategy for the diagnosis, management and prevention of chronic obstructive pulmonary disease, GOLD Executive Summary. Am J Respir Crit Care Med. 2013(4);187:347-365. doi: http://dx.doi.org/10.1164/ rccm.201204-0596PP

2. Ozkaya S, Findik S, Atici AG. The costs of hospitalization in patients with acute exacerbation of chronic obstructive pulmonary disease. Clinicoecon Outcomes Res. 2011;3:15-18. doi: http://dx.doi.org/10.2147/CEOR.S14820

3. Yu AP, Yang H, Wu EQ, Setyawan J, Mocarski M, Blum S. Incremental third-party costs associated with COPD exacerbations: a retrospective claims analysis. $J$ Med Econ. 2011;14(3):315-323. doi: http://dx.doi.org/10.3111/13696998.20 11.576295

4. Toy EL, Gallagher KF, Stanley EL, Swensen AR, Duh MS. The economic impact of exacerbations of chronic obstructive pulmonary disease and exacerbation definition: a review. COPD. 2010;7(3):214-228.

doi: http://dx.doi.org/10.3109/15412555.2010.481697

5. Miravitlles M, Murio C, Guerrero T, Gisbert R; and DAFNE Study Group. Decisiones sobre antibioticoterapia y farmacoeconomía en la EPOC. Pharmacoeconomic evaluation of acute exacerbations of chronic bronchitis and COPD. Chest.2002;121(5):1449-1455.

doi: http://dx.doi.org/10.1378/chest.121.5.1449

6. Soler-Catalu-a JJ, Martínez-García MA, Román Sánchez P, Salcedo E, Navarro M, Ochando R. Severe acute exacerbations and mortality in patients with chronic obstructive pulmonary disease. Thorax.2005; 60(5):925-931.

doi: http://dx.doi.org/10.1136/thx.2005.040527

7. Groenewegen KH, Schols AM, Wouters EF. Mortality and mortality-related factors after hospitalization for acute exacerbation of COPD. Chest.2003;124(2):459-467.

doi: http://dx.doi.org/10.1378/chest.124.2.459

8. Hurst JR, Vestbo J, Anzueto A, et al; and Evaluation of COPD Longitudinally to Identify Predictive Surrogate Endpoints (ECLIPSE) Investigators. Susceptibility to exacerbation in chronic obstructive pulmonary disease. $N$ Engl $J$ Med.2010;363:1128-1138.

doi: http://dx.doi.org/10.1056/NEJMoa0909883

9. Donaldson GC, Seemungal TA, Bhowmik A, Wedzicha JA. Relationship between exacerbation frequency and lung function decline in chronic obstructive pulmonary disease. Thorax. 2002;57(10):847-852.

doi: http://dx.doi.org/10.1136/thorax.57.10.847

10. Kanner RE, Anthonisen NR, Connett JE; and the Lung Health Study Research Group. Lower respiratory illnesses promote FEV1 decline in current smokers but not ex-smokers with mild chronic obstructive pulmonary disease: results from the lung health study. Am J Respir Crit Care Med. 2001;164(3):358-364. doi: http://dx.doi.org/10.1164/ajrccm.164.3.2010017

11. Halpin DM, Decramer M, Celli B, Kesten S, Liu D, Tashkin DP. Exacerbation frequency and course of COPD. Int J Chron Obstruct Pulmon Dis. 2012;7:653-661.

doi: http://dx.doi.org/10.2147/COPD.S34186
12. McAllister DA, Maclay JD, Mills NL, et al. Diagnosis of myocardial infarction following hospitalisation for exacerbation of COPD. Eur Respir J. 2012;395(5):1097-1103.

doi: http://dx.doi.org/10.1183/09031936.00124811

13. Donaldson GC, Hurst JR, Smith CJ, Hubbard RB, Wedzicha JA. Increased risk of myocardial infarction and stroke following exacerbation of COPD. Chest. 2010;137(5):1091-1097. doi: http://dx.doi.org/10.1378/chest.09-2029

14. Seemungal TA, Donaldson GC, Paul EA, Bestall JC, Jeffries DJ, Wedzicha JA. Effect of exacerbation on quality of life in patients with chronic obstructive pulmonary disease. Am J Respir Crit Care Med.1998;157(5 Pt1):1418-1422.

doi: http://dx.doi.org/10.1164/ajrccm.157.5.9709032

15. Anzueto A, Leimer I, Kesten S. Impact of frequency of COPD exacerbations on pulmonary function, health status and clinical outcomes. Int J Chron Obstruct Pulmon Dis. 2009;4:245-251.

16. Global initiative for chronic Obstructive Lung Disease.2011 Global strategy for the diagnosis, management, and prevention of chronic obstructive lung disease. GOLD Website. http:// www.goldcopd.org/guidelines-global-strategy-for-diagnosismanagement.html. Published 2011. Last accessed on March 23, 2013.

17. Donaldson GC, Wilkinson TM, Hurst JR, Perera WR, Wedzicha JA. Exacerbations and time spent outdoors in chronic obstructive pulmonary disease. Am J Respir Crit Care Med. 2005;171(5):446452. doi: http://dx.doi.org/10.1164/rccm.200408-1054OC

18. Bourbeau J. Activities of life: the COPD patient. COPD. 2009;6(3):192-200.

doi: http://dx.doi.org/10.1080/15412550902902638

19. Dault R, Dubé AI, Blais L, et al.Management of chronic obstructive pulmonary disease in patients admitted to atertiary care centre for exacerbation of their disease. Can J Hosp Pharm. 2012;65(5):373-379.

doi: http://dx.doi.org/10.4212/cjhp.v65i5.1175

20. Leuppi JD, Schuetz P, Bingisser R, et al.Short-term vs. conventional glucocorticoid therapy in acute exacerbations of chronic obstructive pulmonary disease: the REDUCE randomized clinical trial. JAMA. 2013;309(21):2223-2231. doi: http://dx.doi.org/10.1001/jama.2013.5023

21. Aaron SD, Vandemheen KL, Maltais F, et al. TNF $\alpha$ antagonists for acute exacerbations of COPD: a randomised double-blind controlled trial. Thorax. 2013;68(2):142-148. doi: http://dx.doi.org/10.1136/thoraxjnl-2012-202432

22. Davis SQ, Permutt Z, Permutt S, et al. Perception of airflow obstruction in patients hospitalized for acute asthma. Ann Allergy Asthma Immunol. 2009;102(6):455-461. doi: http://dx.doi.org/10.1016/S1081-1206(10)60117-2

23. Laforest L, El HA, Pribil C, Ritleng C, Schwalm MS, Van GE. Asthma patients' perception of their ability to influence disease control and management. Ann Allergy Asthma Immunol. 2009;102(5):378-384.

doi: http://dx.doi.org/10.1016/S1081-1206(10)60508-X

24. Seemungal TA, Donaldson GC, Bhowmik A, Jeffries DJ, Wedzicha JA. Time course and recovery of exacerbations in patients with chronic obstructive pulmonary disease. Am J Respir Crit Care Med. 2000;161(5):1608-1613. doi: http://dx.doi.org/10.1164/ajrccm.161.5.9908022 
25. Soler-Cataluna JJ, Rodriguez-Roisin R. Frequent chronic obstructive pulmonary disease exacerbators: how much real, how much fictitious? COPD. 2010;7(4):276-284. doi: http://dx.doi. org/10.3109/15412555.2010.496817

26. Hurst JR, Donaldson GC, Quint JK, Goldring JJ, BaghaiRavary R, Wedzicha JA. Temporal clustering of exacerbations in chronic obstructive pulmonary disease. Am J Respir Crit Care Med. 2009;179(5):369-374. doi: http://dx.doi.org/10.1164/ rccm.200807-1067OC

27. Seemungal T, Harper-Owen R, Bhowmik A, et al. Respiratory viruses, symptoms, and inflammatory markers in acute exacerbations and stable chronic obstructive pulmonary disease. Am J Respir Crit Care Med. 2001;164(9):1618-1623. doi: http://dx.doi.org/10.1164/ajrccm.164.9.2105011

28. Stockley RA, O'Brien C, Pye A, Hill SL. Relationship of sputum color to nature and outpatient management of acute exacerbations of COPD. Chest. 2000;117(6):1638-1645. doi: http://dx.doi.org/10.1378/chest.117.6.1638

29. Papi A, Bellettato CM, Braccioni F, et al. Infections and airway inflammation in chronic obstructive pulmonary disease severe exacerbations. Am J Respir Crit Care Med. 2006;173(10):11141121. doi: http://dx.doi.org/10.1164/rccm.200506-8590C

30. Mallia P, Message SD, Gielen V, et al. Experimental rhinovirus infection as a human model of chronic obstructive pulmonary disease exacerbation. Am J Respir Crit Care Med. 2011;183(6):734742. doi: http://dx.doi.org/10.1164/rccm.201006-08330C

31. Bafadhel M, McKenna S, Terry S, et al. Acute exacerbations of chronic obstructive pulmonary disease: identification of biologic clusters and their biomarkers. Am J Respir Crit Care Med. 2011;184(6):662-671.

doi: http://dx.doi.org/10.1164/rccm.201104-0597OC

32. Anthonisen NR, Manfreda J, Warren CP, Hershfield ES, Harding GK, Nelson NA. Antibiotic therapy in exacerbations of chronic obstructive pulmonary disease. Ann Intern Med. 1987;106(2):196204. doi: http://dx.doi.org/10.7326/0003-4819-106-2-196

33. Rutten FH, Hoes AW. Chronic obstructive pulmonary disease: a slowly progressive cardiovascular disease masked by its pulmonary effects? Eur J Heart Fail. 2012;14(4):348-350. doi: http://dx.doi.org/10.1093/eurjhf/hfs022

34. Chang CL, Robinson SC, Mills GD, et al. Biochemical markers of cardiac dysfunction predict mortality in acute exacerbations of COPD. Thorax. 2011;66(9):764-768. doi: http://dx.doi.org/10.1136/thx.2010.155333

35. Garcia-Aymerich J, Gómez FP, Benet M, et al; and the PACCOPD Study Group. Identification and prospective validation of clinically relevant chronic obstructive pulmonary disease (COPD) subtypes. Thorax. 2011;66(5):430-437. doi: http://dx.doi. org/10.1136/thx.2010.154484

36. Fabbri LM, Beghe B, Agusti A. Cardiovascular mechanisms of death in severe COPD exacerbation: time to think and act beyond guidelines. Thorax. 2011;66(9):745-747. doi: http://dx.doi.org/10.1136/thoraxjnl-2011-200406

37. Niewoehner DE, Lokhnygina Y, Rice K, et al. Risk indexes for exacerbations and hospitalizations due to COPD. Chest. 2007;131(1):20-28. doi: http://dx.doi.org/10.1378/chest.06-1316
38. Burgel PR, Nesme-Meyer P, Chanez P, et al; and the Initiatives Bronchopneumopathie Chronique Obstructive Scientific Committee. Cough and sputum production are associated with frequent exacerbations and hospitalizations in COPD subjects. Chest. 2009;135(4):975-982.

doi: http://dx.doi.org/10.1378/chest.08-2062

39. de Oca MM, Tálamo C, Halbert RJ, et al. Frequency of selfreported COPD exacerbation and airflow obstruction in five Latin American cities: the Proyecto Latinoamericano de Investigacion en Obstruccion Pulmonar (PLATINO) study. Chest. 2009;136(1):71-78. doi: http://dx.doi.org/10.1378/chest.08-2081

40. Wan ES, DeMeo DL, Hersh CP, et al. Clinical predictors of frequent exacerbations in subjects with severe chronic obstructive pulmonary disease (COPD). Respir Med. 2011;105(4):588-594. doi: http://dx.doi.org/10.1016/j.rmed.2010.11.015

41. Mackay AJ, Hurst JR. COPD exacerbations: causes, prevention, and treatment. Med Clin North Am. 2012;96(4):789-809. doi: http://dx.doi.org/10.1016/j.mcna.2012.02.008

42. Hoogendoorn M, Feenstra TL, Hoogenveen RT, Al M, Mölken MR. Association between lung function and exacerbation frequency in patients with COPD. Int J Chron Obstruct Pulmon Dis. 2010;5:435-444. doi: http://dx.doi.org/10.2147/COPD.S13826

43. Faganello MM, Tanni SE, Sanchez FF, Pelegrino NR, Lucheta PA, Godoy I. BODE index and GOLD staging as predictors of 1-year exacerbation risk in chronic obstructive pulmonary disease. Am J Med Sci. 2010;339(1):10-14. doi: http://dx.doi.org/10.1097/MAJ.0b013e3181bb8111

44. Hodgev VA, Kostianev SS, Marinov BA. Correlation of frequency of exacerbations with the BODE index in COPD patients. Folia Med (Plovdiv). 2006;48(2):18-22.

45. Marin JM, Soriano JB, Carrizo SJ, Boldova A, Celli BR. Outcomes in patients with chronic obstructive pulmonary disease and obstructive sleep apnea: the overlap syndrome. Am J Respir Crit Care Med. 2010;182(3):325-331. doi: http://dx.doi.org/10.1164/rccm.200912-18690C

46. Küpeli E, Ulubay G, Ulasli SS, Sahin T, Erayman Z, Gürsoy A. Metabolic syndrome is associated with increased risk of acute exacerbation of COPD: a preliminary study. Endocrine. 2010;38(1):76-82. doi: http://dx.doi.org/10.1007/s12020-010-9351-3

47. Xu W, Collet JP, Shapiro S, et al. Independent effect of depression and anxiety on chronic obstructive pulmonary disease exacerbations and hospitalizations. Am J Respir Crit Care Med. 2008;178(9):913-920.

doi: http://dx.doi.org/10.1164/rccm.200804-6190C

48. Laurin C, Labrecque M, Dupuis G, Bacon SL, Cartier A, Lavoie KL. Chronic obstructive pulmonary disease patients with psychiatric disorders are at greater risk of exacerbations. Psychosom Med. 2009;71(6):667-674. doi: http://dx.doi.org/10.1097/PSY.0b013e3181a82849

49. Quint JK, Baghai-Ravary R, Donaldson GC, Wedzicha JA. Relationship between depression and exacerbations in COPD. Eur Respir J. 2008;32(1):53-60. doi: http://dx.doi.org/10.1183/09031936.00120107 
50. Patel AR, Donaldson GC, Mackay AJ, Wedzicha JA, Hurst JR. The impact of ischemic heart disease on symptoms, health status and exacerbations in COPD. Chest. 2011;141(4):851-857. doi: http://dx.doi.org/10.1378/chest.11-0853

51. Bhowmik A, Seemungal TA, Sapsford RJ, Wedzicha JA. Relation of sputum inflammatory markers to symptoms and lung function changes in COPD exacerbations. Thorax. 2000; 55(2): 114-120. doi: http://dx.doi.org/10.1136/thorax.55.2.114

52. Agustí A, Edwards LD, Rennard SI, et al; and the Evaluation of COPD Longitudinally to Identify Predictive Surrogate Endpoints (ECLIPSE) Investigators. Persistent systemic inflammation is associated with poor clinical outcomes in COPD: A novel phenotype. PLoS One. 2012;7(5):e37483. doi: http://dx.doi.org/10.1371/journal.pone.0037483

53. Patel IS, Seemungal TA, Wilks M, Lloyd-Owen SJ, Donaldson GC, Wedzicha JA. Relationship between bacterial colonisation and the frequency, character, and severity of COPD exacerbations. Thorax. 2002;57(9):759-764. doi: http://dx.doi.org/10.1136/thorax.57.9.759

54. Han MK, Kazerooni EA, Lynch DA, et al; and the COPDGene Investigators. Chronic obstructive pulmonary disease exacerbations in the COPDGene study: associated radiologic phenotypes. Radiology. 2011;261(1):274-282. doi: http://dx.doi.org/10.1148/radiol.11110173

55. Wells JM, Washko GR, Han MK, et al; and the COPDGene Investigators and the ECLIPSE Study Investigators. Pulmonary arterial enlargement and acute exacerbations of COPD. $N$ Engl J Med. 2012;367:913-921. doi: http://dx.doi.org/10.1056/NEJMoa1203830

56. Calverley PM, Anderson JA, Celli B, et al; and theTORCH investigators. Salmeterol and fluticasone propionate and survival in chronic obstructive pulmonary disease. $N$ Engl $J$ Med. 2007;356:775-789. doi: http://dx.doi.org/10.1056/NEJMoa063070

57. Tashkin DP, Celli B, Senn S, Burkhart D, Kesten S, Menjoge S, Decramer $\mathrm{M}$; and the UPLIFT Study Investigators. A 4-year trial of tiotropium in chronic obstructive pulmonary disease. $N$ Engl J Med. 2008;359:1543-1554. doi: http://dx.doi.org/10.1056/ NEJMoa0805800

58. Suissa S, Dell'aniello S, Ernst P. Long-term natural history of chronic obstructive pulmonary disease: severe exacerbations and mortality. Thorax. 2012;67(11):957-963. doi: http://dx.doi. org/10.1136/thoraxjnl-2011-201518

59. Eaton T, Young P, Fergusson W, et al. Does early pulmonary rehabilitation reduce acute health-care utilization in COPD patients admitted with an exacerbation? A randomized controlled study. Respirology.2009;14(2):230-238.

doi: http://dx.doi.org/10.1111/j.1440-1843.2008.01418.x

60. Yip NH, Yuen G, Lazar EJ, et al. Analysis of hospitalizations for COPD exacerbation: opportunities for improving care. COPD. 2010;7(2):85-92. doi: http://dx.doi.org/10.3109/15412551003631683

61. Rennard SI, Higenbottam T. Exacerbation-free COPD: a goal too far? Proc Am Thorac Soc. 2007;4(8):583-585. doi: http:// dx.doi.org/10.1513/pats.200707-098TH
62. Makris D, Bouros D. COPD exacerbation: lost in translation. BMC Pulm Med. 2009; 9:6. doi: http://dx.doi.org/10.1186/14712466-9-6

63. Burge S, Wedzicha JA. COPD exacerbations: definitions and classifications. Eur Respir J Suppl. 2003;41:46s-53s. doi: http://dx.doi.org/10.1183/09031936.03.00078002

64. Leidy NK, Wilcox TK, Jones PW, Roberts L, Powers JH, Sethi S; and the EXACT-PRO Study Group. Standardizing measurement of chronic obstructive pulmonary disease exacerbations. Reliability and validity of a patient-reported diary. Am J Respir Crit Care Med. 2011;183(3):323-329. doi: http://dx.doi.org/10.1164/rccm.201005-0762OC

65. Aaron SD, Fergusson D, Marks GB, et al; and the Canadian Thoracic Society/Canadian Respiratory Clinical Research Consortium. Counting, analyzing and reporting exacerbations of COPD in randomised controlled trials. Thorax. 2008;63(2):122128. doi: http://dx.doi.org/10.1136/thx.2007.082636

66. Au DH, Bryson CL, Chien JW, et al. The effects of smoking cessation on the risk of chronic obstructive pulmonary disease exacerbations. J Gen Intern Med. 2009;24(4):457-463. doi: http:// dx.doi.org/10.1007/s11606-009-0907-y

67. Roberts D, Cole P. Effect of tobacco and nicotine on growth of Haemophilus influenzae in vitro. J Clin.Pathol. 1979; 32(7): 728731. doi: http://dx.doi.org/10.1136/jcp.32.7.728

68. Puhan MA, Gimeno-Santos E, Scharplatz M, Troosters T,Walters EH, Steurer J. Pulmonary rehabilitation following exacerbations of chronic obstructive pulmonary disease. Cochrane Database Syst Rev. 2011;(10).

69. Seymour JM, Moore L, Jolley CJ, et al. Outpatient pulmonary rehabilitation following acute exacerbations of COPD. Thorax. 2010;65:423-428. doi: http://dx.doi.org/10.1136/thx.2009.124164

70. Kiyohara K, Kojimahara N, Sato Y, Yamaguchi N. Changes in COPD mortality rate after amendments to the Preventive Vaccination Law in Japan. Eur J Public Health.2011;23(1):133-139. doi: http://dx.doi.org/10.1093/eurpub/ckr172

71. Poole PJ, Chacko E, Wood-Baker RW, Cates CJ. Influenza vaccine for patients with chronic obstructive pulmonary disease. Cochrane Database Syst Rev. 2000;(4).

72. Varkey JB, Varkey AB, Varkey B. Prophylactic vaccinations in chronic obstructive pulmonary disease: current status. Curr Opin Pulm Med. 2009;15(2):90-99.

doi: http://dx.doi.org/10.1097/MCP.0b013e3283218356

73. Furumoto A, Ohkusa Y, Chen M, et al. Additive effect of pneumococcal vaccine and influenza vaccine on acute exacerbation in patients with chronic lung disease. Vaccine. 2008; 26(33): 4284-4289.

doi: http://dx.doi.org/10.1016/j.vaccine.2008.05.037

74. Poole PJ, Chacko E, Wood-Baker RW, Cates CJ. Influenza vaccine for patients with chronic obstructive pulmonary disease. Cochrane Database Syst Rev. 2006;(1).

75. Wedzicha JA, Decramer M, Seemungal TA. The role of bronchodilator treatment in the prevention of exacerbations of COPD. Eur Respir J. 2012;40(6):1545-1554. doi: http://dx.doi. org/10.1183/09031936.00048912 
76. Stockley RA, Whitehead PJ, Williams MK. Improved outcomes in patients with chronic obstructive pulmonary disease treated with salmeterol compared with placebo/usual therapy: results of a meta-analysis. Respir Res.2006;7:147. doi: http://dx.doi. org/10.1186/1465-9921-7-147

77. Yohannes AM, Willgoss TG, Vestbo J. Tiotropium for treatment of stable COPD: a meta-analysis of clinically relevant outcomes. Respir Care. 2011;56(4): 477-487. doi: http://dx.doi.org/10.4187/ respcare.00852

78. Celli BR. [What is the best pharmacological treatment to prevent exacerbation of chronic obstructive pulmonary disease?] (article in Polish). Pol Arch Med Wewn. 2008;118:172-174.

79. Van den Bruel A, Gailly J, Neyt M. Does tiotropium lower exacerbation and hospitalization frequency in COPD patients: results of a meta-analysis. BMC Pulm Med. 2010;10:50.

80. Vogelmeier C, Hederer B, Glaab T, et al. Tiotropium versus salmeterol for the prevention of exacerbations of COPD. $N$ Engl J Med. 2011; 364:1093-1103. doi: http://dx.doi.org/10.1056/ NEJMoa1008378

81. Decramer ML, Chapman KR, Dahl R, et al; and the INVIGORATE investigators. Once-daily indacaterol versus tiotropium for patients with severe chronic obstructive pulmonary disease (INVIGORATE): a randomised, blinded, parallel-group study. Lancet Respir Med. 2013;1(7): 524-533. doi: http://dx.doi. org/10.1016/S2213-2600(13)70158-9

82. Jones PW, Rennard SI, Agusti A, et al. Efficacy and safety of once-daily aclidinium in chronic obstructive pulmonary disease. Respir Res. 2011;12:55. doi: http://dx.doi.org/10.1186/14659921-12-55

83. D’Urzo A, Ferguson GT, van Noord JA, et al. Efficacy and safety of once-daily NVA237 in patients with moderate-to-severe COPD: the GLOW1 trial. Respir Res. 2011;12:156. doi: http://dx.doi.org/10.1186/1465-9921-12-156

84. Wedzicha JA, Decramer M, Ficker JH, et al. Analysis of chronic obstructive pulmonary disease exacerbations with the dual bronchodilator QVA149 compared with glycopyrronium and tiotropium (SPARK): a randomised, double-blind, parallel-group study. Lancet Respir Med. 2013;1(3):199-209. doi: http://dx.doi. org/10.1016/S2213-2600(13)70052-3

85. Cosio BG, Iglesias A, Rios A, Noguera A, Sala E, Ito K, Barnes PJ, Agusti A. Low-dose theophylline enhances the antiinflammatory effects of steroids during exacerbations of COPD. Thorax. 2009;64(5):424-429.

doi: http://dx.doi.org/10.1136/thx.2008.103432

86. Barnes PJ. Inhaled corticosteroids in COPD: a controversy. Respiration. 2010;80(2):89-95.

doi: http://dx.doi.org/10.1159/000315416

87. Barnes PJ, Ito K, Adcock IM. Corticosteroid resistance in chronic obstructive pulmonary disease: inactivation of histone deacetylase. Lancet. 2004;363(9410):731-733. doi: http://dx.doi.org/10.1016/S0140-6736(04)15650-X

88. Ito $\mathrm{K}$, Ito $\mathrm{M}$, Elliott WM, et al. Decreased histone deacetylase activity in chronic obstructive pulmonary disease. $N$ Engl $J$ Med. 2005;352:1967-1976.

doi: http://dx.doi.org/10.1056/NEJMoa041892
89. Sobieraj DM, White CM, Coleman CI. Benefits and risks of adjunctive inhaled corticosteroids in chronic obstructive pulmonary disease: a meta-analysis. Clin Ther. 2008;30(8):14161425. doi: http://dx.doi.org/10.1016/j.clinthera.2008.08.004

90. Loke YK, Cavallazzi R, Singh S. Risk of fractures with inhaled corticosteroids in COPD: systematic review and meta-analysis of randomised controlled trials and observational studies. Thorax. 2011;66(8):699-708. doi: http://dx.doi.org/10.1136/thx.2011.160028

91. Agarwal R, Aggarwal AN, Gupta D, Jindal SK. Inhaled corticosteroids vs placebo for preventing COPD exacerbations: a systematic review and metaregression of randomized controlled trials. Chest. 2010;137(2):318-325. doi: http://dx.doi.org/10.1378/chest.09-1305

92. Global initiative for chronic Obstructive Lung Disease.2014 Global Strategy for the Diagnosis, Management, and Prevention of Chronic Obstructive Pulmonary Disease. GOLD Website. http://www.goldcopd.org. Published January 2014. Accessed September 8, 2014.

93. Dransfield MT, Bourbeau J, Jones PW, et al. Once-daily inhaled fluticasone furoate and vilanterol versus vilanterol only for prevention of exacerbations of COPD: two replicate doubleblind, parallel-group, randomised controlled trials. Lancet Respir Med. 2013;1(3):210-223. doi: http://dx.doi.org/10.1016/ S2213-2600(13)70040-7

94. Szafranski W, Cukier A, Ramirez A, et al. Efficacy and safety of budesonide/formoterol in the management of chronic obstructive pulmonary disease. Eur Respir J. 2003;21(1):74-81. doi: http://dx.doi.org/10.1183/09031936.03.00031402

95. Calverley PM, Boonsawat W, Cseke Z, Zhong N, Peterson $\mathrm{S}$, Olsson H. Maintenance therapy with budesonide and formoterol in chronic obstructive pulmonary disease. Eur Respir J. 2003;22(6):912-919. doi: http://dx.doi.org/10.1183/09031936.0 3.00027003

96. Siva R, Green RH, Brightling CE, et al. Eosinophilic airway inflammation and exacerbations of COPD: a randomised controlled trial. Eur Respir J. 2007;29(5):906-913. doi: http:// dx.doi.org/10.1183/09031936.00146306

97. Bafadhel M, McKenna S, Terry S, et al. Blood eosinophils to direct corticosteroid treatment of exacerbations of chronic obstructive pulmonary disease. Am J Respir Crit Care Med. 2012; 186(1):4855. doi: http://dx.doi.org/10.1164/rccm.201108-15530C

98. Sin DD, Tashkin D, Zhang X, et al. Budesonide and the risk of pneumonia: a meta-analysis of individual patient data. Lancet. 2009;374(9691):712-719.

doi: http://dx.doi.org/10.1016/S0140-6736(09)61250-2

99. Janson C, Larsson K, Lisspers KH, et al. Pneumonia and pneumonia related mortality in patients with COPD treated with fixed combinations of inhaled corticosteroid and long acting $\beta 2$ agonist: observational matched cohort study (PATHOS). BMJ. 2013;346.

100. Jung KS, Park HY, Park SY, et al; and the Korean Academy of Tuberculosis and Respiratory Diseases study group; Korea Chronic Obstructive Pulmonary Disease Study Group. Comparison of tiotropium plus fluticasone propionate/ salmeterol with tiotropium in COPD: a randomized controlled study. Respir Med. 2012:106(3):382-389. doi: http://dx.doi.org/10.1016/j.rmed.2011.09.004 
101.Um SW, Yoo CG, Kim YW, Han SK, Shim YS. The combination of tiotropium and budesonide in the treatment of chronic obstructive pulmonary disease. J Korean Med Sci. 2007;22(5): 839-845. doi: http://dx.doi.org/10.3346/jkms.2007.22.5.839

102. Fang LZ, Liang X, Zhang JQ, Liu L, Fu WP, Zhao ZH, Dai LM. [Combination of inhaled salmeterol/fluticasone and tiotropium in the treatment of chronic obstructive pulmonary disease: a randomised controlled trial] (article inChinese). Zhonghua Jie He He Hu Xi Za Zhi. 2008; 31(11):811-814.

103.Welte T, Miravitlles M, Hernandez P, et al. Efficacy and tolerability of budesonide/formoterol added to tiotropium in patients with chronic obstructive pulmonary disease. Am J Respir Crit Care Med. 2009;180:741-750. doi: http://dx.doi. org/10.1164/rccm.200904-0492OC

104. Aaron SD, Vandemheen KL, Fergusson D, et al; and the Canadian Thoracic Society/Canadian Respiratory Clinical Research Consortium. Tiotropium in combination with placebo, salmeterol, or fluticasone-salmeterol for treatment of chronic obstructive pulmonary disease: a randomized trial. Ann Intern Med. 2007;146(8):545-555. doi: http://dx.doi.org/10.7326/00034819-146-8-200704170-00152

105. Rodrigo GJ, Plaza V, Castro-Rodríguez JA. Comparison of three combined pharmacological approaches with tiotropium monotherapy in stable moderate to severe COPD: a systematic review. Pulm Pharmacol Ther. 2012; 25(1):40-47. doi: http:// dx.doi.org/10.1016/j.pupt.2011.10.006

106.Calverley PM, Rabe KF, Goehring UM, Kristiansen S, Fabbri LM, Martinez FJ; and the M2-124 and M2-125 study groups. Roflumilast in symptomatic chronic obstructive pulmonary disease: two randomised clinical trials. Lancet. 2009; 374(9691):685-694. doi: http://dx.doi.org/10.1016/S01406736(09)61255-1

107.Bateman ED, Rabe KF, Calverley PM, et al. Roflumilast with long-acting $\beta 2$-agonists for COPD: influence of exacerbation history. Eur Respir J. 2011; 38(3):553-560. doi: http://dx.doi. org/10.1183/09031936.00178710

108.Fabbri LM, Calverley PM, Izquierdo-Alonso JL, et al; and the M2-127 and M2-128 study groups. Roflumilast in moderate-tosevere chronic obstructive pulmonary disease treated with longacting bronchodilators: two randomised clinical trials. Lancet. 2009; 374(9691):695-703. doi: http://dx.doi.org/10.1016/ S0140-6736(09)61252-6

109.Rennard SI, Calverley PM, Goehring UM, Bredenbröker D, Martinez FJ. Reduction of exacerbations by the PDE 4 inhibitor roflumilast--the importance of defining different subsets of patients with COPD. Respir Res. 2011;12:18. doi: http://dx.doi. org/10.1186/1465-9921-12-18

110.Bateman E, Jardim J, Goehring UM, Brose M, Calverley P. Effect of roflumilast on hospitalizations in COPD patients. Eur Respir J. 2012;40(Suppl 56):P2109.

111.Fabbri L, Goehring UM, Brose M, Rabe K. Effects of roflumailast in highly symptomatic COPD patients. Eur Respir J. 2012; 40(Suppl 56): P742.

112. Wedzicha JA, Rabe KF, Martinez FJ, et al. Efficacy of roflumilast in the COPD frequent exacerbator phenotype. Chest. 2013;143(5):1302-1311. doi: http://dx.doi.org/10.1378/ chest.12-1489
113. Sethi S, Murphy TF. Infection in the pathogenesis and course of chronic obstructive pulmonary disease. $N$ Engl $J$ Med.2008;359:2355-2365. doi: http://dx.doi.org/10.1056/NEJMra0800353

114.Martínez-Solano L, Macia MD, Fajardo A, Oliver A, Martinez JL. Chronic Pseudomonas aeruginosa infection in chronic obstructive pulmonary disease. Clin Infect Dis. 2008;47(12):15261533. doi: http://dx.doi.org/10.1086/593186

115.Seemungal TA, Wilkinson TM, Hurst JR, Perera WR, Sapsford RJ, Wedzicha JA. Long-term erythromycin therapy is associated with decreased chronic obstructive pulmonary disease exacerbations. Am J Respir Crit Care Med. 2008;178(11):11391147. doi: http://dx.doi.org/10.1164/rccm.200801-145OC

116.Albert RK, Connett J, Bailey WC, et al; and the COPD Clinical Research Network. Azithromycin for prevention of exacerbations of COPD. N Engl J Med. 2011;365:689-698. doi: http://dx.doi.org/10.1056/NEJMoa1104623

117. Sethi S, Jones PW, Theron MS, et al; and the PULSE Study group. Pulsed moxifloxacin for the prevention of exacerbations of chronic obstructive pulmonary disease: a randomized controlled trial. Respir Res. 2010;11:10. doi: http://dx.doi.org/10.1186/14659921-11-10

118. Miravitlles M, Marín A, Monsó E, et al. Efficacy of moxifloxacin in the treatment of bronchial colonisation in COPD. Eur Respir J. 2009; 34(5):1066-1071. doi: http://dx.doi. org/10.1183/09031936.00195608

119.Lawes CM, Thornley S, Young R, et al. Statin use in COPD patients is associated with a reduction in mortality: a national cohort study. Prim Care Respir J. 2012;21(1):35-40. doi: http:// dx.doi.org/10.4104/pcri.2011.00095

120.Søyseth V, Brekke PH, Smith P, Omland T. Statin use is associated with reduced mortality in COPD. Eur Respir J. 2007;29(2):279283. doi: http://dx.doi.org/10.1183/09031936.00106406

121. Blamoun AI, Batty GN, DeBari VA, Rashid AO, Sheikh M, Khan MA. Statins may reduce episodes of exacerbation and the requirement for intubation in patients with COPD: evidence from a retrospective cohort study. Int J Clin Pract. 2008;62(9):13731378. doi: http://dx.doi.org/10.1111/j.1742-1241.2008.01731.x

122. Huang CC, Chan WL, Chen YC, et al. Statin use and hospitalization in patients with chronic obstructive pulmonary disease: a nationwide population-based cohort study in Taiwan. Clin Ther. 2011;33(10):1365-1370. doi: http://dx.doi. org/10.1016/j.clinthera.2011.08.010

123. Dransfield MT, Rowe SM, Johnson JE, Bailey WC, Gerald LB. Use of $\beta$-blockers and the risk of death in hospitalised patients with acute exacerbations of COPD. Thorax. 2008;63(4):301-305. doi: http://dx.doi.org/10.1136/thx.2007.081893

124.Ekström MP, Hermansson AB, Ström KE. Effects of cardiovascular drugs on mortality in severe chronic obstructive pulmonary disease. Am J Respir Crit Care Med. 2013;187(7):715720. doi: http://dx.doi.org/10.1164/rccm.201208-1565OC

125.MacNee W. Oxidants/antioxidants and COPD. Chest. 2000;117(5 Suppl 1):303S-317S. doi: http://dx.doi.org/10.1378/chest.117.5_ suppl_1.303S-a 
126. Decramer M, Rutten-van Mölken M, Dekhuijzen PN, et al. Effects of N-acetylcysteine on outcomes in chronic obstructive pulmonarydisease (Bronchitis Randomized on NAC CostUtility Study, BRONCUS): a randomised placebo-controlled trial. Lancet. 2005;365(9470):1552-1560.

doi: http://dx.doi.org/10.1016/S0140-6736(05)66456-2

127.Zheng JP, Kang J, Huang SG, et al. Effect of carbocisteine on acute exacerbation of chronic obstructive pulmonary disease (PEACE Study): a randomised placebo-controlled study. Lancet. 2008; 371(9629):2013-2018. doi: http://dx.doi.org/10.1016/ S0140-6736(08)60869-7

128. Mackay AJ, Donaldson GC, Patel AR, Singh R, Kowlessar $\mathrm{B}$, Wedzicha JA. Detection and severity grading of COPD exacerbations using the exacerbations of chronic pulmonary disease tool (EXACT). Eur Respir J. 2014;43(3):735-744. doi: http://dx.doi.org/10.1183/09031936.00110913

129. Marin JM, Carrizo SJ, Casanova C, et al. Prediction of risk of COPD exacerbations by the BODE index. Respir Med. 2009;103(3):373-378.

doi: http://dx.doi.org/10.1016/j.rmed.2008.10.004

130.Brusse-Keizer M, van der Palen J, van der Valk P, Hendrix R, Kerstjens H. Clinical predictors of exacerbation frequency in chronic obstructive pulmonary disease. Clin Respir J. 2011;5(4):227-234.

doi: http://dx.doi.org/10.1111/j.1752-699X.2010.00234.x

131.Dodd JW, Hogg L, Nolan J, et al. The COPD assessment test (CAT): response to pulmonary rehabilitation. A multicentre, prospective study. Thorax. 2011;66(5):425-429. doi: http://dx.doi. org/10.1136/thx.2010.156372

132.National Institutes of Health. Effect of QVA149 versus NVA237 and tiotropium on chronic obstructive pulmonary disorder (COPD) exacerbations (SPARK). NCT01120691. clinicaltrials. gov Web site. http://www.clinicaltrials.gov/ct2/show/NCTO11 20691?term=NCTo1120691.\&rank=1. Published 2010. Updated 2013. Accessed September 8, 2014.

133. Chatterjee A, Shah M, D’Souza AO, Bechtel B, Crater G, Dalal AA. Observational study on the impact of initiating tiotropium alone versus tiotropium with fluticasone propionate/salmeterol combination therapy on outcomes and costs in chronic obstructive pulmonary disease. Respir Res. 2012;13:15. doi: http://dx.doi.org/10.1186/1465-9921-13-15 